\title{
PROCESSAMENTOS DE AMÊNDOA E TORTA DE CASTANHA-DO-BRASIL E FARINHA DE MANDIOCA: PARÂMETROS DE GUALIDADE ${ }^{1}$
}

\author{
Maria Luzenira de SOUZA², Hilary Castle de MENEZES ${ }^{3, *}$
}

\begin{abstract}
RESUMO
A castanha-do-Brasil (Bertholletia excelsa H.B.K.) e mandioca (Manihot esculenta Crantz) são matérias-primas importantes que constituem a base de subsistência para os povos da região Amazônica. Devido à falta de incentivo às suas utilizações pela indústria de alimentos no mercado interno, buscou-se processar a castanha-do-Brasil para obtenção de amêndoa e torta, e de mandioca para obtenção de farinha, objetivando identificar parâmetros de qualidade que justificassem e incentivassem o apelo aos seus aproveitamentos. Os resultados mostraram que a negatividade de aflatoxinas na amêndoa e torta apontaram a alta qualidade do lote da castanha-do-Brasil em relação a segurança alimentar. Os teores encontrados de selênio $2,04 \mathrm{mg} / \mathrm{kg}$ na amêndoa e $7,13 \mathrm{mg} / \mathrm{kg}$ na torta, os percentuais de fibra alimentar de 8,02 na amêndoa, de 15,72 na torta e de 5,68 na farinha, proteína bruta de $40,23 \%$ na torta e carboidratos $79,33 \%$ na farinha, permitiram caracterizar o produto a base de castanha como protéico, rico em selênio e fibras; e o de mandioca como rico em carboidratos e fibras. A proteína bruta da amêndoa é completa, rica em aminoácidos sulfurados, estando uns aminoácidos em quantidades superiores e outros equivalentes aos do padrão da FAO, podendo a castanha e derivados - devido a estes aminoácidos, ao selênio e fibras - serem considerados um apelo ao seu consumo, pelas funções de grande relevância que desempenham à manutenção da saúde do ser humano.

Palavras-chave: castanha-do-Brasil; proteínas; aminoácido; selênio; fibra.
\end{abstract}

\section{SUMMARY}

PROCESSING OF BRAZIL NUT AND MEAL AND CASSAVA FLOUR: QUALITY PARAMETERS. Brazil nut (Bertholletia excelsa H.B.K.) and cassava (Manihot esculenta Crantz) are important raw materials, which constitute the basis of subsistence for those who live in the Amazon region. Due to a total lack of incentive for their use by the national food industry, this study aimed at processing Brazil nuts to obtain the nuts and the meal and at processing cassava to obtain the flour, studying the quality parameters which could justify and encourage their use. The absence of aflatoxin in both the nuts and meal indicated the high quality of the Brazil nuts with respect to food safety. The presence of a selenium content of $2.04 \mathrm{mg} / \mathrm{Kg}$ in the nut and $7.13 \mathrm{mg} / \mathrm{Kg}$ in the meal, a food fiber content of $8.02 \%$ in the nut, $15.72 \%$ in the meal and $5.68 \%$ in the flour, a protein content of $40.23 \%$ in the meal and carbohydrate content of $79.33 \%$ in the flour allowed for the characterization of products based on the nut as high protein, rich in selenium and fiber and of the cassava as rich in carbohydrate and fiber. The protein of the nut is complete and rich in sulfur amino acids and contains all the essential amino acids, some with values greater than and others equal to, the FAO standards. Due to these contents of amino acids, selenium and fiber, the consumption of the Brazil nut and derivatives should be encouraged due to their relevant functions with respect to human health. Keywords: Brazil nuts; protein; amino acid; selenium; fiber.

\section{1 - INTRODUÇÃO}

\section{1 - Castanha-do-Brasil}

A castanheira-do-Brasil (Bertholletia excelsa, H.B.K.) é originária da região Amazônica. Apresenta porte majestoso e frondoso, com copa dominante na região onde se encontra, chegando a medir cerca de 30 - 50 metros de altura e 5 metros de diâmetro na base do tronco [2, 9, 17, 35, 37, 40]. Plantas provenientes de sementes podem iniciar a frutificação aos oito anos e somente aos doze anos, atingem a produção normal, desde que sejam plantadas a céu aberto, enquanto as castanheiras enxertadas podem iniciar a produção de frutos aos 3,5 anos [39].

\footnotetext{
1. Recebido para publicação em 07/01/2003. Aceito para publicação em 08/01/2004 (001047).

2. Departamento de Ciências Agrárias/Unidade de Tecnologia de Alimentos da Universidade Federal do Acre, Campus Universitário BR 364, km 4. CEP 69915-900, Rio Branco-AC. E-mail: luzenira@ufac.br.

3. Departamento de Tecnologia de Alimentos da Faculdade de Engenharia de Alimentos da UNICAMP. Caixa Postal 6121, CEP 13083-970, Campinas-SP. E-mail: hilary@fea.unicamp.br.

*A quem a correspondência deve ser enviada.
}

O consumo desta amêndoa no mercado interno é muito pequeno estimando-se que seja apenas $1 \%$ da sua produção [47, 62]. A maior parte é exportada in natura, para os países da Europa (Alemanha e Inglaterra) e América do Norte (Estados Unidos) [47, 63].

A amêndoa de castanha-do-Brasil apresenta a seguinte composição química centesimal em g/100g: umidade 4,40, proteína bruta 17,00, lipídios 67,00, carboidratos 7,00 , valor energético $751 \mathrm{kcal}$ e sais minerais 3,60, em média [22]. Segundo Castro apud TEIXEIRA [59] a fração albumina, a excelsina, é a única completa de origem vegetal conhecida, o que levou a castanhado-Brasil ser chamada de carne vegetal.

É uma amêndoa oleaginosa de elevado valor energético, rica em proteínas de alto valor biológico. Apresenta muitos outros constituintes indispensáveis a uma boa alimentação, como o selênio, antioxidante que vem sendo referido na prevenção de câncer, doenças cardiovascular e muitas outras. A concentração desse elemento na amêndoa varia de região para região onde a planta vegeta. Para redução do elevado valor energético e/ou calórico das amêndoas de castanha-do-Brasil, se faz necessário a obtenção da torta parcialmente ou completamente desengordurada, através da extração do material graxo. A torta apresenta 
inúmeras possibilidades de aplicação, visando o enriquecimento de uma grande variedade de grupos de alimentos, tais como: produtos para panificação, bebidas, embutidos, farinhas, leites, cereais, snacks, salgados, doces, sorvetes, chocolates, biscoitos, bombons, além de muitos outros.

\section{2 - Mandioca}

A mandioca é uma planta dicotiledônea, da família Euphorbiaceae e gênero Manihot, originária das Américas. Este gênero apresenta um grande número de espécies, mas, a única cultivada para fins alimentícios é a Manihot esculenta Crantz [13] que pode ser da variedade brava ou mansa, devido ao teor de glicosídios cianogênicos (que liberam o ácido cianídrico) presente. Os compostos cianogênicos por si sós não são tóxicos; o ácido cianídrico liberado a partir da linamarina encontrada na mandioca, pela ação das enzimas betaglicosidase e hidroxinitrilo liase, é o responsável pela toxidez, sendo a dose letal desse ácido para a espécie humana de 0,5 a $3,5 \mathrm{mg} / \mathrm{kg}$ de peso vivo [8]. A reação ocorre quando o tecido vegetal é triturado, como no processamento ou na ingestão, permitindo o contato entre o substrato e a enzima. O parecer da comunidade cientifica européia reconhece o limite de $50 \mathrm{mg} / \mathrm{kg}$ de ácido cianídrico (glucosídio cianogênico) como critério para distinguir a variedade doce da amarga [64].

A mandioca é utilizada nos mais diversos campos da atividade econômica, destacando-se seu uso na alimentação humana, principalmente pelas populações dos países em desenvolvimento, que são os seus maiores produtores e consumidores [23]. Dentre os muitos subprodutos obtidos da mandioca, a farinha é considerada o principal produto processado, absorvendo cerca de 70 a $80 \%$ da produção mundial da raiz [20], destinando-se em grande parte ao comércio interno, não apresentando valor relevante como produto de exportação [33].

A farinha de mandioca é definida como: o produto obtido das raízes provenientes de plantas da família Euphorbiaceae, gênero Manihot, submetida a processo tecnológico adequado de fabricação e beneficiamento. O padrão de identidade e qualidade deve apresentar no máximo: umidade $13 \%$, resíduo mineral fixo $1,5 \%$, aci$\operatorname{dez} 3,0 \mathrm{~mL}$ de soluto alcalino normal/100g e no mínimo 70\% de substância amilácea [11].

Os sistemas de produção e de transformação desta raiz e seus derivados apresentam grande diversidade tecnológica, variando-se desde os pequenos cultivos em quintal, à produção tradicional dos pequenos agricultores das zonas semi-áridas do Nordeste e regiões Amazônicas até as produções em larga escala das farinheiras da região Sul do Brasil, que utilizam a colheita semi-mecanizada [21].

O objetivo deste trabalho foi processar amêndoa e torta de amêndoa de castanha-do-Brasil e farinha de mandioca, visando identificar parâmetros de qualidade que justificassem e incentivassem seus aproveitamentos pela indústria de alimentos.

\section{2 - MATERIAL E MÉTODOS}

\section{1 - Matérias-primas}

Utilizaram-se $70 \mathrm{~kg}$ de castanha-do-Brasil com casca, safra 2001, obtidas de lote a granel armazenado na Cooperativa Agro-Extrativista de Xapuri-CAEX-AC e $100 \mathrm{~kg}$ de mandioca in natura com casca, adquirida na CEASA de Campinas - SP.

\section{2 - Processamento de castanha-do-Brasil in natu- ra com casca para obtenção de amêndoa e torta}

Experimento 1. Processamento de castanha in natura para obtenção de amêndoa

Foi realizado na Usina de beneficiamento de castanha-do-Brasil da CAEX-Ac, de acordo com SOUZA [53], conforme Fluxograma da Figura 1.

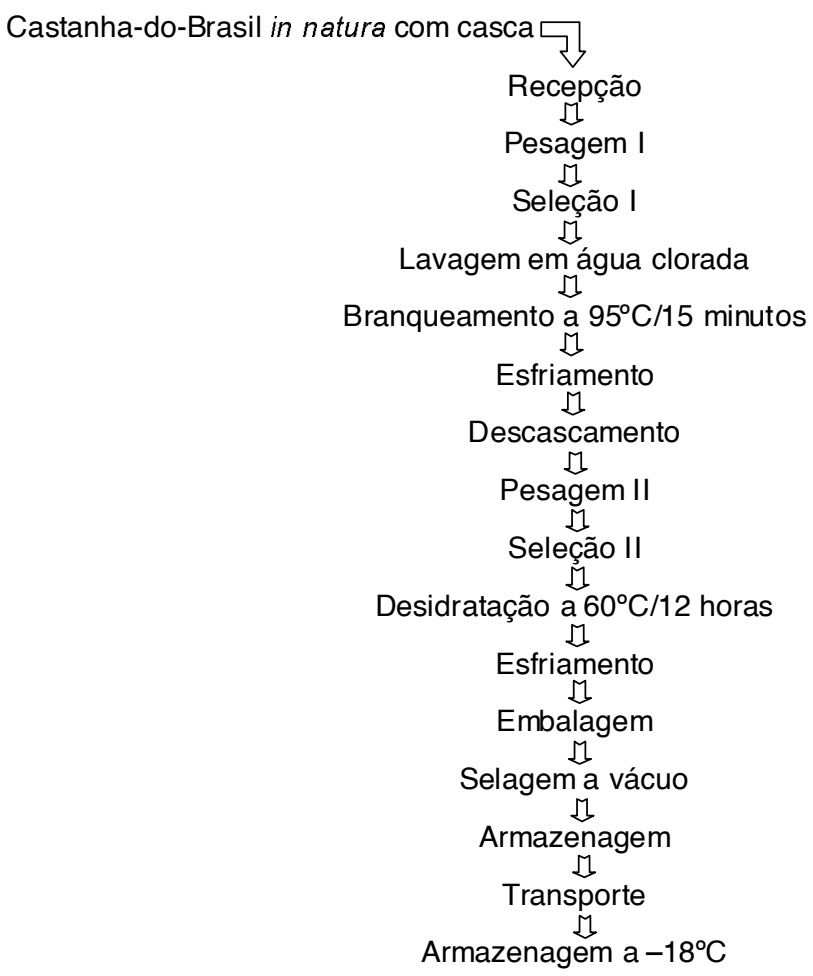

FIGURA 1. Fluxograma do processamento de castanha-doBrasil in natura com casca para obtenção de amêndoa.

Experimento 2. Processamento de amêndoas de castanha-do-Brasil para obtenção de torta de amêndoa desengordurada por prensagem

Inicialmente desenvolveram-se vários testes experimentais por prensagem para extração de óleo da amêndoas, que foram submetidas a diferentes pressões em kgf e tempos, em prensa hidráulica manual marca Charlott, disponivel na Planta Piloto de Frutas do DTA/ FEA/UNICAMP, visando a obtenção de baixo percentual de óleo na torta. Também foi realizado no Instituto de Tecnologia de Alimentos-ITAL em Campinas-SP, utilizando-se uma prensa elétrica de rosca sem fim, marca Ecirtec modelo MP-40, conforme Fluxograma da Figura 2. 


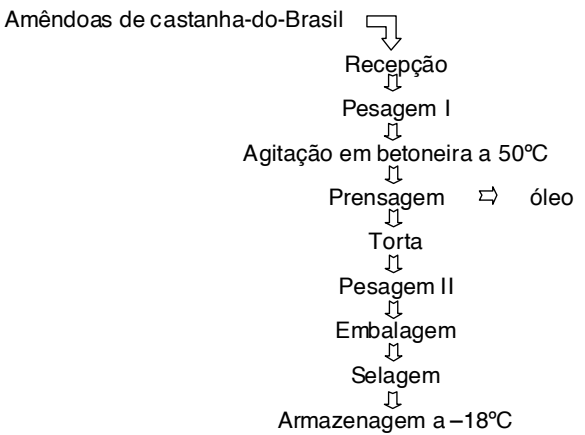

FIGURA 2. Fluxograma do processamento de amêndoa de castanha-do-Brasil para obtenção de torta de amêndoa desengordurada.

Experimento 3. Processamento de re-extração de óleo de torta de amêndoas de castanha-do-Brasil.

Para reduzir mais o óleo da torta de amêndoa, realizou-se outra prensagem, utilizando prensa hidráulica manual marca Charlott, na Planta Piloto de Processamento de Frutas do DTA/FEA/UNICAMP, conforme Fluxograma da Figura 3.

Torta de amêndoa de castanha-do-Brasil 马

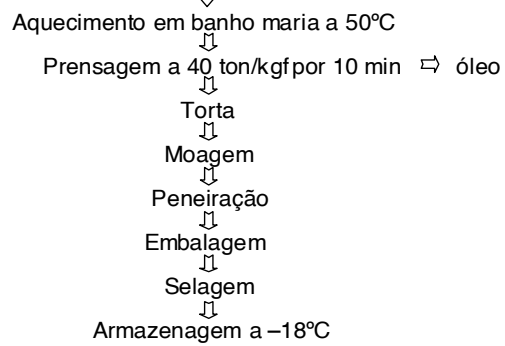

FIGURA 3. Fluxograma do processamento de re-extração de óleo de torta de amêndoa de castanha-do-Brasil.

\section{3 - Processamento de mandioca in natura para obtenção de farinha}

Realizou-se na Planta Piloto de Processamento de Frutas do DTA/FEA/UNICAMP, conforme o Fluxograma da Figura 4.

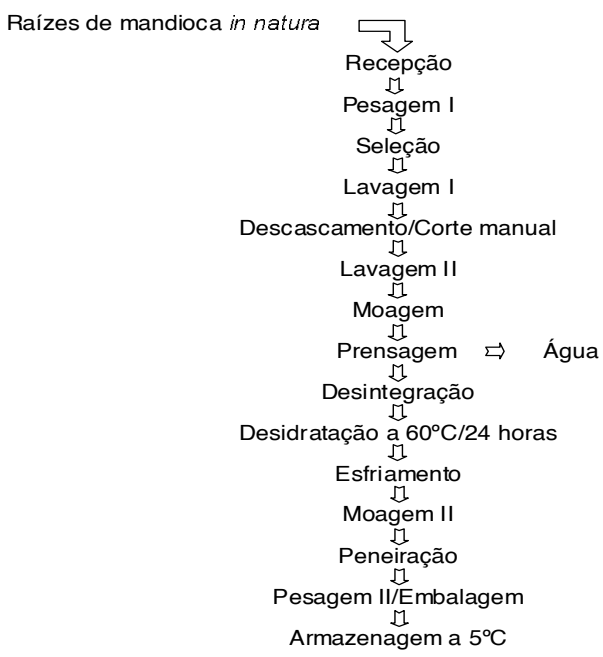

FIGURA 4. Fluxograma do processamento de mandioca in natura para obtenção de farinha.

\section{4 - Análises realizadas na amêndoa e torta de amêndoa de castanha-do-Brasil}

\subsection{1 - Análises de aflatoxinas, selênio e com- posição química}

As determinações de aflatoxinas $B_{1}, B_{2}, G_{1}$ e $G_{2}$ foram efetuadas por cromatografia em camada delgada, segundo a metodologia descrita por RODRIGUEZ AMAYA \& VALENTE SOARES [48]. Os limites de detecção do método são de $3 \mu$ g. $\mathrm{kg}^{-1}$ para $\mathrm{B}_{1}, 2 \mu \mathrm{g} . \mathrm{kg}^{-1}$ para $\mathrm{B}_{2}, 3 \mu \mathrm{g} . \mathrm{kg}^{-1}$ para $\mathrm{G}_{1}$ e $2 \mu \mathrm{g} . \mathrm{kg}^{-1}$ para $\mathrm{G}_{2}$. Os teores de selênio foram determinados por espectrometria de emissão atômica em plasma de argônio indutivamente acoplada, conforme metodologia reportado por OLSON, PALMER \& CARY [41] e IMO INDUSTRIES INC. BAIRD ANALYTICAL INSTRUMENTS DIVISION [30]. Para determinação da composição química realizou-se análises de umidade, lipídios, cinzas e proteínas (método micro-Kjeldhal utilizando o fator 5,46 x $\% \mathrm{~N}$ ) seguindo os procedimentos da AACC [1]; a rancidez oxidativa pelo método do IAL [29]; aminoácidos totais e livres, segundo técnica descrita por SPACKMAN, STEIN \& MOORE [55]; triptofano, conforme método de SPIES [56]; fibras alimentares solúvel, insolúvel e total pelo método enzimático segundo AOAC [7] e carboidratos estimados por diferença (subtraindo-se de 100 o somatório de proteínas, lipídios, cinzas, umidade e fibra alimentar total). A energia metabolizável, em kcal foi obtida a partir dos dados de composição centesimal, usando os fatores de conversão de Atwater de 4kcal/100g para carboidratos e proteínas e 9kcal/100g para lipídios [6]. Todas as determinações foram realizadas em triplicatas e os resultados expressos em g/100g.

\subsection{2 - Escore químico das proteínas}

O escore químico foi calculado a partir da determinação de aminoácidos essenciais, onde cada um dos aminoácidos da proteína em estudo foi dividido pelo teor de cada aminoácido essencial correspondente ao padrão de referência da FAO/WHO/UNU [25], para crianças de 2 A 5 anos. O aminoácido para o qual a proteína apresentou o escore mais baixo foi considerado o escore químico da proteína e obtido pela fórmula:

$$
\mathrm{EQ}=\frac{\mathrm{g} \text { aminoácidos / 100g proteína }}{\text { Padrão FAO/WHO/UNU* [25] }} \times 100
$$

*Transformado de mg aminoácido / grama de proteína para g aminoácido / 100g de proteína.

\section{5 - Análises realizadas na farinha de mandioca}

A composição química da farinha de mandioca foi determinada seguindo as mesmas recomendações descritas para a amêndoa e torta de castanha-do-Brasil.

\section{3 - RESULTADOS E DISCUSSÃO}

\section{1 - Obtenção de amêndoa e de torta de amêndoa de castanha-do-Brasil desengordurada e de farinha de mandioca}

Os processos de obtenções de amêndoa e torta de amêndoa de castanha-do-Brasil e de farinha de man- 
dioca estão apresentado nos Fluxogramas das Figuras 1,2 e 3 . O resultado de lipídios obtidos na torta de amêndoa de castanha-do-Brasil, após a re-extração do óleo foi de 25,13\% (Tabela 1). Neste caso, as prensas utilizadas para remoção dos lipídios da amêndoa não se mostraram eficientes para a produção de torta desengordurada (com o máximo de 5\% de lipídio residual) ou seja, uma torta contendo um teor residual de óleo que possibilitasse seu emprego individual para processamento por extrusão. A farinha de raízes de mandioca in natura foi obtida conforme as operações descritas no Fluxograma da Figura 4 e os resultados da composição química estão apresentados na Tabela 1.

\section{2 - Resultados das análises da amêndoa, da torta de amêndoa de castanha-do-Brasil e da farinha de mandioca}

A Tabela 1 apresenta os resultados das análises de aflatoxinas $B_{1}, B_{2}, G_{1}$ e $G_{2}$, selênio, composição centesimal e valor calórico da amêndoa e torta de castanha-doBrasil e composição centesimal da farinha de mandioca.

TABELA 1. Composição química centesimal, teor de selênio, aflatoxinas e valor calórico da amêndoa e torta de amêndoa de castanha-do-Brasil e composição centesimal da farinha de mandioca

\begin{tabular}{lccc}
\hline \multicolumn{1}{c}{ Componente } & $\begin{array}{c}\text { Farinha de } \\
\text { mandioca }\end{array}$ & $\begin{array}{c}\text { Amêndoa de } \\
\text { castanha-do-Brasil }\end{array}$ & $\begin{array}{c}\text { Torta de amêndoa de } \\
\text { castanha-do-Brasil }\end{array}$ \\
\hline Umidade (\%) & $12,78 \pm 0,02$ & $3,13 \pm 0,01$ & $6,70 \pm 0,00$ \\
Cinzas (\%) & $0,74 \pm 0,00$ & $3,84 \pm 0,01$ & $8,85 \pm 0,00$ \\
Lipídios (\%) & $0,26 \pm 0,02$ & $67,30 \pm 0,02$ & $25,13 \pm 0,00$ \\
Proteínas (\%) & $1,21 \pm 0,05$ & $14,29 \pm 0,00$ & $40,23 \pm 0,03$ \\
Carboidratos (\%) & $79,33 \pm 0,01$ & $3,42 \pm 0,06$ & $3,37 \pm 0,04$ \\
Fibra total (\%) & $5,68 \pm 0,02$ & $8,02 \pm 0,02$ & $15,72 \pm 0,02$ \\
Fibra insolúvel (\%) & $4,51 \pm 0,02$ & $4,89 \pm 0,03$ & $12,67 \pm 0,09$ \\
Fibra solúvel (\%) & $1,17 \pm 0,03$ & $3,12 \pm 0,01$ & $3,04 \pm 0,07$ \\
Valor calórico (kcal) & $324,56 \pm 0,22$ & $676,56 \pm 0,18$ & $400,60 \pm 0,09$ \\
Selênio (mg/kg) & Não realizado & $2,04 \pm 0,01$ & $7,13 \pm 0,04$ \\
Aflatoxina $B_{1}$ & Não realizado & Não Detectado & Não Detectado \\
Aflatoxina $B_{2}$ & Não realizado & Não Detectado & Não Detectado \\
Aflatoxina $\mathrm{G}_{1}$ & Não realizado & Não Detectado & Não Detectado \\
Aflatoxina $\mathrm{G}_{2}$ & Não realizado & Não Detectado & Não Detectado \\
\hline \hline
\end{tabular}

A não detecção de aflatoxinas $B_{1}, B_{2}, G_{1}$ e $G_{2}$ na amêndoa do lote estudado e na torta de castanha-doBrasil processada, comprovou sua qualidade em relação à segurança alimentar, pois a ausência indica que estes produtos encontram-se próprios para o consumo humano, em relação aos metabólitos tóxicos analisados. Tais substâncias podem ser encontradas em vários grupos de alimentos, especialmente oleaginosas como a castanha-do-Brasil in natura e processada, amendoim e outros alimentos. De acordo com SANTÚRIO [51], das micotoxinas conhecidas, as aflatoxinas são as mais tóxicas, principalmente a aflatoxina $B_{1}$.

As aflatoxinas produzidas pelos fungos dos gêneros Aspergillus flavus e Aspergillus parasiticus, são alta- mente tóxicas e carcinogênicas e provocam câncer do fígado, mesmo estando presentes em quantidades muito pequenas $(\mu \mathrm{g})$ [53]. SABBATINI [49] relata que castanha-do-Brasil já teve grandes remessas proibidas de entrar nos Estados Unidos, por estarem contaminadas com aflatoxinas e que as paçoquinhas de amendoim, são verdadeiras bombas ambulantes, pois, geralmente, são processadas com amendoim contaminado com aflatoxinas ou de qualidade inferior, rejeitado para comercialização in natura. Comenta que os seus fabricantes cometem um verdadeiro "atentado contra a saúde da população".

A presença de aflatoxinas nos alimentos destinados ao consumo humano supõe um risco óbvio potencial para a saúde pública [4]. A presença de aflatoxinas os tornam inadequados para o consumo humano e animal. Amostras de carne, leite e ovos provenientes de animais alimentados com rações que contenham aflatoxinas, têm apresentado as toxinas ou seus derivados em seus produtos [12, 32, 45].

Portanto, podemos inferir que devido à ausência das aflatoxinas $B_{1}, B_{2}, G_{1}$ e $G_{2}$, na amêndoa e torta estudada, sugere-se que nestes e nos derivados provenientes deste lote, ocorrerá ausência de aflatoxinas, desde que sejam mantidas as boas práticas de processamento e armazenagem. No Brasil, a Resolução nº 34/1976/MS [10] fixa a tolerância de $30 \mathrm{ppb}$ de aflatoxinas para alimentos. Deve-se ressaltar, entretanto, que o limite permitido no Brasil é um dos maiores existentes na legislação mundial, por isso é recomendável que se trabalhe teores inferiores àquele limite máximo permitido, devido à alta periculosidade desses metabólitos tóxicos.

O teor de selênio encontrado na amêndoa de castanha-do-Brasil foi de $2,04 \mathrm{mg} / \mathrm{kg}$ (correspondente a $204 \mu \mathrm{g} / 100 \mathrm{~g})$, teor que não ultrapassou a dose UL de $400 \mu \mathrm{g}$ UL (máximo nível tolerável de ingestão de selênio/dia sem riscos de efeitos adversos) [61], estando dentro da média dos valores encontrados por CHANG et al. [19], que analisaram individualmente dois lotes de 162 amêndoas de castanha-do-Brasil, um proveniente da região do Acre/Rondônia e o outro da região de Manaus/Belém, encontraram concentrações de selênio (mg/kg), variando entre 3,06 a 4,01 para as do Acre/ Rondônia e 36,0 a 50,0 para as Manaus/Belém. PALMER \& HERR [43] analisaram individualmente 529 castanhasdo-Brasil e encontraram valores de 0,0 a $497 \mathrm{mg} / \mathrm{kg}$ de selênio, sendo que $45,32 \%$ de castanhas apresentavam selênio na faixa de 0,0 a $9,9 \mathrm{mg} / \mathrm{kg}$.

A quantidade de selênio encontrada na torta de castanha-do-Brasil foi de $7,13 \mathrm{mg} / \mathrm{kg}$, sendo 3,56 vezes maior que o teor da amêndoa. Isto pode ser explicado pela grande quantidade de amêndoas com película utilizada para obtenção da torta e ao seu menor percentual de lipídio, sugerindo-se que a película da amêndoa poderá possivelmente, conter elevada concentração de selênio. Não foram encontrados na literatura dados sobre o teor de selênio na torta desta amêndoa.

O selênio é um oligoelemento essencial à saúde. No caso de doenças crônicas como a aterosclerose, cân- 
cer, artrite, cirrose e efisema, há fortes indícios de que ele atue como elemento protetor. Por muitos anos, o selênio foi considerado tóxico para animais, quando ingerido em altas doses. Recentemente descobriu-se que em quantidades muito pequenas ele é necessário na dieta [16]. O selênio retarda o envelhecimento, combate a tensão pré-menstrual, preserva a elasticidade dos tecidos, previne o câncer e neutraliza os radicais livres. Em homens, aumenta a potência e o interesse sexual e supre a carência gerada quando o selênio é perdido com o sêmen [3].

Pesquisas assinalam que mais de um quarto dos casos de câncer de esôfago e estômago, em Lixian na China, são de caráter epidêmico e podem ser atribuídos aos baixos níveis de selênio na população. MARK et al. [36], examinaram através de estudos em população humana a associação entre os niveis séricos de selênio e o desenvolvimento de câncer escamoso de esôfago e adenocarcinoma gástrico e de acordo com os resultados obtidos calcularam que $26,4 \%$ dos casos de câncer das cárdias (orifícios que permitem a passagem do conteúdo esofagiano para o estômago) podem ser atribuídos a baixos níveis de selênio no sangue. Esses autores especulam com a possibilidade das conclusões do estudo conduzirem a decisão de suplementar com selênio, em forma massiva a população da China, da mesma forma em que se suplementa com flúor ou folato em outros países, já que a incidência de câncer de esôfago e de estômago na China é proporcionalmente alta.

O aporte alimentar diário de selênio varia de um país para outro, 200ug para os canadenses e somente $30 \mu \mathrm{g}$ para os Filandeses. Na França, o aporte médio/ dia é de 46ug. O Conselho Nacional Americano de Pesquisas preconiza $1 \mu \mathrm{g}$ por quilo de peso corporal ao dia. CHANG et al. [19], afirmam que cerca de 0,5 a 1,0 $\mu \mathrm{g} /$ $\mathrm{kg} /$ peso de selênio na dieta é suficiente para os requerimentos dietéticos em humanos. Estudos recentes têm mostrado que a inclusão de castanha-do-Brasil na dieta de ratos que receberam administração intragástrica do carcinógeno mamário, dimetilbenzen(a)antracene (DMBA), reduziu o número de tumores acima de $72,7 \%$, $[31,34]$. Castanha-do-Brasil é naturalmente muito rica em selênio. A proteção contra formação de tumor foi acreditada devido seu alto conteúdo de selênio, desde que a amêndoa da planta nogueira a substituiu em dietas controle, mostrando nenhuma redução significativa na formação de tumor [29].

Existem estudos que indicam que em regiões onde há carência de selênio no solo, aparecem cardiopatias e alguns tipos de câncer. Os requerimentos diários são da ordem de 50 a $75 \mu \mathrm{g}$ para mulher e homem adultos. A ingestão de uma dieta equilibrada satisfaz às necessidades diárias. Um regime carente de selênio induziu catarata em animais, e não se pode deixar de associar a relação entre a carência de selênio em velhos, freqüentemente desnutridos, e o aparecimento da catarata [67].

Selênio é o oligoelemento por excelência. Há alguns anos atrás, se desconfiava de seu papel essencial, mas não se tinha ainda a prova. Tudo mudou de- pois da descoberta chinesa da ação do selênio para curar a doença de Keshan, uma cardiopatia infantil. Pesquisadores neozelandeses conseguiram curar com o aporte de selênio as distrofias neuro-musculares de quem apresentou esse problema na reanimação [66]. O selênio possui, ainda um efeito antídoto com relação aos metais pesados tóxicos, como o mercúrio, o chumbo, o arsênico e o cádmio. Pesquisas em curso colocam em evidência as propriedades anti-inflamatórias e imunoestimulantes do selênio [65].

Experimentos em animais mostraram que o selênio em altas doses é tóxico e cancerígeno; entretanto, em baixas doses, inibiu o progresso dos tumores mamários nas ratazanas e diminuiu o desenvolvimento do câncer do cólon e também protegeu fumantes impedindo a transformação de certos produtos cancerígenos (benzopireno da fumaça do tabaco) [66].

Há evidências de patologias que podem induzir perdas de selênio: alcoólicas - hiper-consumo hepático de selênio para compensar a produção exagerada de radicais livres durante o metabolismo do etanol; eliminação excessiva de selênio pela pele, nas numerosas patologias dermatológicas; pessoas desnutridas, em particular idosos; pacientes com nutrição parenteral em reanimação [65].

Embora os valores de selênio nos alimentos variem realmente de uma região para outra, devido à quantidade deste mineral presente nos solos, os valores elevados já encontrados na castanha e amêndoa não sinalizam problemas de toxidez ao homem, de modo que a castanha é um dos alimentos básicos do homem que habita a floresta amazônica, consumindo-a das mais variadas formas, tanto pura como misturada com outros alimentos como peixes, carnes, café, mandioca e nunca se teve relatos de problemas de toxidez naqueles habitantes e, por outro lado RAYMAN [46] abordar que a toxidez com selênio é muito pouco conhecida devido ao mecanismo de regulação fisiológica.

PARIZEK [42] relata que a avaliação de dados em animais são insuficientes para permitir reconhecer a carcinogenicidade de selênio e dados disponíveis com humanos não sugerem que o selênio é carcinogênico ao homem. Em 1980 foram publicados estudos pelo Instituto Nacional do Câncer dos Estados Unidos, indicando os efeitos carcinogênicos em ratos e camundongos depois de administrar sulfito de selênio comercial, usado como ingrediente em certos shampoos anti-caspa.

O selênio se encontra naturalmente nos alimentos de origem animal, frutos do mar, carnes, fígado, rim, vegetais e cereais integrais, sendo a castanha-doBrasil o alimento mais rico neste mineral.

Os percentuais de proteínas 14,29 e 40,23, fibra alimentar total 8,02 e 15,72; lipídios 67,30 e 25,13, encontrados na amêndoa e torta de amêndoa de castanha-do-Brasil encontram-se na Tabela 1. GLÓRIA \& REGITANO D'ARCE [27] trabalhando com torta, concentrado e isolado protéico de castanha-do-Brasil desengordurada por prensagem e posteriormente com 
solvente hexano, encontraram percentuais de $47,6 \%$ de proteína na torta; $59,3 \%$ de proteína no concentrado; $81,6 \%$ de proteína no isolado; $5,5 \%$ de fibra bruta na torta; $9,1 \%$ de fibra bruta no concentrado; $0,7 \%$ de fibra bruta no isolado; $1,2 \%$ de lipídios na torta; 1,4 de lipídios no concentrado e $0,2 \%$ de lipídios no isolado.

Entende-se que a diferença entre os valores encontrados pelos autores e os deste trabalho, deve ter sido devida a vários fatores como: a origem e tipo da castanha utilizada para obtenção da torta, de forma que se utilizou neste trabalho amêndoas integrais com toda a película marrom, aos métodos de extração de óleo da amêndoa para obtenção da torta, resultando em um elevado percentual de material graxo nesta torta e ao tipo de torta que as autoras trabalharam, (torta desengordurada por prensagem seguida por solvente hexano), onde foi extraído praticamente todo material graxo.

O teor de lipídios encontrado na amêndoa (67,30\%) está dentro dos valores encontrados por SOUZA et al. [54], SANTOS [50], CAMARGO [14] e HART \& FISHER [28]. Nesta torta foi encontrado $25,13 \%$ de lipídio, resultado considerado alto, uma vez que objetivava-se obter um menor teor residual de óleo, visando a obtenção de uma torta protéica vegetal, com menos calorias provenientes de lipídios. No entanto, este constituinte é importante do ponto de vista nutricional, de modo que SOUZA [53] e TATEO [58] afirmam que o maior componente da fração graxa da amêndoa de castanha-doBrasil é o ácido graxo linoléico, reconhecido universalmente como ácido graxo essencial, de grande relevância para alimentação humana.

Os valores de fibra alimentar total encontrados na amêndoa $(8,02 \%)$ e torta $(15,72 \%)$ foram bem mais elevados do que os observados por GLÓRIA \& REGITANO D'ARCE [27], o que pode ter sido devido à origem da matéria-prima, presença de película marrom na amêndoa, variabilidade genética, grau de maturação e ao método enzimático utilizado na análise deste trabalho. Estes resultados são desejáveis do ponto de vista nutricional. Os teores de fibras insolúveis foram maiores do que os de fibras solúveis na amêndoa e torta de castanha, conforme Tabela 1.

Fibra alimentar é a soma de todos os polissacarídeos de vegetais (celulose, hemicelulose, pectinas, gomas e mucilagens), mais lignina, que não são hidrolisados pelas enzimas do trato-digestivo humano. Para fins práticos as fibras da dieta podem ser agrupadas em duas grandes categorias, conforme a solubilidade de alguns componentes em água: insolúveis (são os polissacarídeos estruturais: celulose, lignina e hemicelulose) e solúveis (os não estruturais) as quais têm mostrado efeitos fisiológicos bastante diferentes.

As fibras insolúveis diminuem o tempo de trânsito intestinal, aumentam o volume fecal, tornam a absorção de glicose mais lenta e retardam a hidrólise do amido. As fibras solúveis retardam o esvaziamento gástrico, aumentam o tempo de trânsito intestinal, tornando a absorção da glicose mais lenta. Os componentes não estruturais são de vários compostos, sendo muito importantes os ricos em ácido urônico- substâncias pécticas, mistura complexa de polissacarídeos coloidais. Podem aparecer ainda na fração indigerivel, gomas e mucilagens, nem sempre originadas dos vegetais, mas adicionadas durante o processamento, principalmente para dar textura ao produto como goma agar, carragena, guar. As frações pécticas da fibra são significativamente hipocolesterolemizantes, bem como as gomas e mucilagens [15, 18, 44, 60].

ANDERSON [5] mostra em seus estudos que as fibras da dieta são benéficas ao organismo, pois diminuem o colesterol plasmático total, a lipoproteína LDL-colesterol e os triglicérides plasmáticos, além de favorecerem a saciedade e a perda de peso corporal. As fibras solúveis (encontradas principalmente em feijões, na aveia e farelos) se sobressaem quanto ao efeito hipocolesterolêmico.

Os resultados de umidade, proteína bruta, lipídio e cinzas encontrados na farinha de mandioca apresentados na Tabela 1, estão de acordo com os citados por LIMA [33] e com o padrão de identidade e qualidade da farinha de mandioca de: no máximo $13 \%$ de umidade e 1,5\% de resíduo mineral fixo, e no mínimo $70 \%$ de substâncias amiláceas, conforme Portaria no 554 de 30/08/ 1995 MA [11]. Os percentuais de umidade da amêndoa 3,13 e torta de amêndoa 6,70 estão bem abaixo dos valores máximos recomendados para grãos (12\%), sendo assim pode-se dizer que são produtos estáveis.

Em relação ao valor calórico, pôde-se observar que a farinha de mandioca apresentou $324,56 \mathrm{kcal} / 100 \mathrm{~g}$, a torta de castanha $400,60 \mathrm{kcal} / 100 \mathrm{~g}$ e a amêndoa $676,56 \mathrm{kcal} /$ 100g. O maior valor para a amêndoa foi devido ao alto percentual de lipídio que contribuiu para elevar o seu valor energético, enquanto que na torta, devido à extração de lipídios, o valor calórico reduziu. Estes resultados estão de acordo com os relatados por Campos et al., Rodrigues, Hawley \& Carden, Cooper et al., apud SOUZA [52] para amêndoa de castanha e FRANCO [26] para farinha de mandioca.

Os aminoácidos totais encontrados na amêndoa e torta de castanha-do-Brasil estão expressos na Tabela 2. Os teores na amêndoa estão de acordo com os resultados observados por SRUR [57] e CAMARGO [14], em relação aos tipos dos aminoácidos totais, exceto para o triptofano que SRUR [57] não determinou, diferindo nos teores, de forma que os valores encontrados neste trabalho foram bem maiores.

Analisando-se o escore químico verificou-se que a amêndoa apresentou proteína completa, onde todos os valores dos escores químicos dos aminoácidos essenciais encontraram-se superiores aos do padrão teórico da FAO [24].

Os resultados dos teores de aminoácidos essenciais verificados na torta (Tabela 2) foram inferiores aos encontrados por GLORIA \& REGITANO D'ARCE [27], porém estas autoras não determinaram triptofano e histidina, o que pode ter sido ocasionado pela presença de película marrom na amêndoa da amostra analisada neste trabalho. 
TABELA 2. Aminoácidos totais e livres encontrados na amêndoa e torta de castanha-do-Brasil (em g aa/100g proteína) nestas amostras e de outros autores.

\begin{tabular}{|c|c|c|c|c|c|c|c|c|}
\hline \multirow[b]{2}{*}{$\begin{array}{l}\text { AA/PTN } \\
(\mathrm{g} / 100 \mathrm{~g})\end{array}$} & \multicolumn{3}{|c|}{ Amêndoa/aa totais } & \multirow{2}{*}{$\begin{array}{l}\begin{array}{l}\text { Amêndoa } \\
\text { aa/Livres }\end{array} \\
\text { Amostra }^{1}\end{array}$} & \multicolumn{2}{|c|}{ Torta/aa totais } & \multicolumn{2}{|c|}{$\begin{array}{c}\text { Dados da FAO } \\
{[24,25]}\end{array}$} \\
\hline & Amostra $^{1}$ & $\begin{array}{c}\text { CAMARGO } \\
{[14]}\end{array}$ & $\begin{array}{c}\text { SRUR } \\
\text { [57] }\end{array}$ & & Amostra & $\begin{array}{c}1 \text { GLÓRIA \& } \\
\text { D'ARCE [27] }\end{array}$ & Padrão ${ }_{\text {aa }}^{2}$ & Teórico \\
\hline Ac. asp & 10,11 & 3,13 & 3,70 & 0,03 & 6,49 & ND & - & - \\
\hline $\operatorname{Thr}^{\mathrm{E}}$ & 3,02 & 1,18 & 0,97 & 0,05 & 1,79 & 3,16 & 3,40 & 40 \\
\hline Ser & 5,24 & 1,50 & 1,86 & ND & 3,29 & ND & - & \\
\hline Ac glu & 25,01 & 11,02 & 12,92 & 0,02 & 16,82 & ND & - & \\
\hline Prol & 4,76 & 0,81 & 1,80 & 0,05 & 2,80 & ND & - & \\
\hline Gly & 5,72 & 2,78 & 2,03 & 0,10 & 3,59 & ND & - & \\
\hline Aly & 4,32 & 2,29 & 1,49 & 0,03 & 2,60 & ND & - & \\
\hline $\mathrm{Val}^{\mathrm{E}}$ & 5,12 & 3,33 & 1,66 & 0,04 & 3,65 & 5,92 & 3,50 & 50 \\
\hline $\operatorname{Met}^{E}$ & 7,12 & 2,70 & 2,82 & 0,03 & 5,38 & 9,55 & & \\
\hline$\stackrel{+}{\text { Cys }^{E}}$ & 2,33 & 0,86 & 0,84 & ND & 1,86 & ND & $* * 2,50$ & **35 \\
\hline$\| e^{E}$ & 3,09 & 2,13 & 1,19 & 0,10 & 2,55 & 3,75 & 2,80 & 40 \\
\hline $\operatorname{Leu}^{\mathrm{E}}$ & 8,58 & 4,54 & 3,28 & 0,10 & 5,34 & 8,71 & 6,60 & 70 \\
\hline Tyr $^{\mathrm{E}}$ & 3,23 & 1,46 & 1,01 & ND & 1,84 & ND & - & \\
\hline $\mathrm{Phe}^{+}$ & 4,90 & 2,50 & 1,49 & ND & 2,87 & 4,92 & - & ${ }^{*} 60$ \\
\hline Lys $^{E}$ & 4,53 & 2,72 & 1,00 & 0,03 & 2,31 & 3,71 & 5,80 & 55 \\
\hline $\mathrm{NH}_{3}$ & 2,01 & 1,29 & 0,83 & 0,01 & 1,47 & ND & - & \\
\hline $\mathrm{His}^{\mathrm{E}}$ & 3,11 & 2,31 & 0,79 & 0,01 & 2,06 & ND & 1,90 & \\
\hline $\operatorname{Trp}^{\mathrm{E}}$ & 1,10 & 0,87 & ND & $\mathrm{NI}$ & 0,71 & ND & 1,10 & 10 \\
\hline $\operatorname{Arg}$ & 17,30 & 8,26 & 5,32 & 0,26 & 11,39 & ND & - & \\
\hline $\mathrm{EQ}$ & Comp & - & - & - & 40 Lys & Comp & - & - \\
\hline
\end{tabular}

Ac. asp - Ácido aspártico; Thr - Treonina; Serina - Ser; Ac. glu - Ácido glutâmico; Prol - Prolina; Gly - Glicina; Aly - Alanina; Val - Valina; Met - Metionina; Cys - Cisteina; Histidina; Trp - Triptofano; Arg - Arginina; *Tirosina (Tyr) + Fenilalanina (Phe); **
Metionina (Met) + Cisteina (Cys); E - Essenciais; EQ - Escore quimico; AA/PTN Metionina (Met) + Cisteína (Cys); E - Essenciais; EQ - Escore químico; AA/PTN Aminoácidos na proteína; aa - Aminoácido; ${ }^{1}$ Material desengordurada; ${ }^{2} \mathrm{Fonte}-\mathrm{FAO} /$
WHO/UNU [25] para pré-escolares de 2 a 5 anos de idade, (transformados de mg aa/g de proteína para $\mathrm{g}$ aa/100g proteína); ${ }^{3} \mathrm{Fonte}-\mathrm{FAO} / \mathrm{WHO} / \mathrm{UNU}[24]$ valores cansformados de mg aa/g de proteína para g aa/loog proteína; NI - não identificado; ND - não determinado;Comp - Completa.

Calculando-se os escores químicos dos aminoácidos da torta do trabalho reportado pelas citadas autoras, observou-se que todos os escores químicos obtidos foram superiores aos do padrão teórico da FAO [24], tendo sido a proteína daquela torta completa. Entretanto, existem variações na composição química dos alimentos em função de diversos fatores como variedade, grau de maturação do fruto, adubação, fatores edafoclimáticos, fatores genéticos, metodologia empregada e outros, o que podem justificar a diferença encontrada, aliada a origem e condições da amostra de torta estudada.

Todos os aminoácidos totais encontrados na torta foram em percentuais menores que os achados na amêndoa (Tabela 2), o que pode ser justificado pela presença de elevada quantidade de película marrom presente na torta, que elevou o percentual de fibras totais e cinzas, reduzindo os de aminoácidos. Já os aminoácidos essenciais estavam todos presentes com valores acima dos do padrão teórico da FAO [24], apenas para valina, metionina+cisteína e histidina, conforme mostrados na Tabela 2. Entretanto, avaliando-se os escores químicos (EQ) dos aminoácidos da referida torta, encontrou-se o EQ inferior ao padrão teórico da FAO apenas em relação a lisina, correspondendo a 40 contra 55 do padrão do escore químico teórico citado. Mesmo assim, vários autores classificam a proteína da castanha-do-Brasil como um dos alimentos vegetais mais completos [59].
Estudos mostram que a proteína de farinha de castanha-do-Pará foi superior à proteína isolada da soja e inferior à caseína em ensaios realizados com ratos [38].

CAMARGO [14] enfoca que "tendo em vista os aminoácidos presentes na castanha e, principalmente, ao fato de conter aqueles considerados essenciais, inclusive o triptofano, pode-se afirmar a sua excelência entre os alimentos vegetais". Neste contexto e corroborando com o referido autor, sugerimos que a amêndoa, torta e derivados de castanha-do-Brasil poderão servir como ótima base protéica na alimentação humana, devendo suprir deficiências deste nutriente na alimentação.

SRUR [57] afirma que a elevada concentração em metionina na proteína da castanha é um dado que merece ser considerado no equilíbrio aminoácido das dietas infantis artificiais, geralmente deficientes em aminoácidos sulfurados. A Tabela 2 apresenta as quantidades de metionina + cisteína (aminoácidos sulfurados) encontradas na amêndoa $(9,45 \mathrm{~g}$ aa/ $100 \mathrm{~g}$ proteína) e na torta $(7,24 \mathrm{~g}$ aa/ $100 \mathrm{~g}$ proteína) estando acima de $2,50 \mathrm{~g}$ aa/100g de proteína, estabelecido pelo padrão da $\mathrm{FAO} / \mathrm{WHO} / \mathrm{UNU}$ [25].

\section{4 - CONCLUSÕES}

Não foi encontrada a presença de aflatoxinas $B_{1}$, $\mathrm{B}_{2}, \mathrm{G}_{1}, \mathrm{G}_{2}$ na amêndoa e torta de castanha-do-Brasil do lote analisado.

Os teores de selênio encontrados na amêndoa e torta de amêndoa de castanha-do-Brasil foram de $2,04 \mathrm{mg} / \mathrm{kg}$, na amêndoa e $7,13 \mathrm{mg} / \mathrm{kg}$ na torta.

Os teores de fibra alimentar total encontrados na farinha de mandioca, amêndoa e torta de amêndoa de castanha-do-Brasil podem ser considerados satisfatórios, sendo um apelo ao seu consumo diário devido seus benefícios a saúde humana.

A proteína da amêndoa e torta de amêndoa de castanha-do-Brasil é rica em todos aminoácidos essenciais, com elevado teor dos sulfurados (metionina e cisteína), geralmente insuficientes em proteínas vegetais. Sugere-se sua mistura com outras matérias-primas com o objetivo de enriquecê-las em qualidade e quantidade protéicas.

Na torta de amêndoa do lote estudado, os aminoácidos essenciais encontram-se em valores acima do padrão teórico da Food and Agriculture Organization of the United Nations/FAO [25], com exceção de treonina, isoleucina, leucina, lisina, e triptofano, entretanto o escore químico inferior ao estabelecido pelo padrão da FAO [24] foi apenas em relação ao do aminoácido lisina.

Os produtos processados: amêndoa e torta de amêndoa de castanha-do-Brasil e a farinha de mandioca apresentam elevados valores calóricos, sendo a torta um produto característico protéico de origem vegetal devido ao alto teor de proteína bruta, além de rico em selênio e fibra, devendo ser aproveitada no enriquecimento de alimentos. 


\section{5 - REFERÊNCIAS BIBLIOGRÁFICAS}

[1] AACC - AMERICAN ASSOCIATION OF CEREAL CHEMISTS. Approved Methods of the AACC. $9^{\text {th }}$. Saint Paul, v.1 - 2, 1995.

[2] ALMEIDA, C. P. Castanha-do-pará, sua exportação e importância na economia amazônica. SAI n. 19. Rio de Janeiro: Ministério da Agricultura, 1963. 86 p.

[3] ALVAREnGA, R. M. Palavra de médico. Tudo o que você deve saber sobre as novas Fontes da Juventude. Disponivel em: <http://www.palaurademedico.cjb.net/>. Acesso em: 26 Ago. 2002.

[4] AMADO, M. A. Aflatoxinas: um problema mundial. Disponível em: <http://www.ipv.pt/millenium/ 16_spec6.htm>. Acesso em 26/08/2002

[5] ANDERSON, J. W.; KRITCHRVISK, D.; BONFIELD, C. Dietery Fiber: Chemistry, Physiology and Health Effects. New York, 1990. 500p.

[6] ANDERSON, L. A.; DIBBle, M. V.; TURKKI, P. R.; MITCHELL, H. S.; RYNBERGEN, H. J. Nutrição. Trad. Nádia M. F. Truggo. Rio de Janeiro: Guanabara, 1988. Cap. 10, p. 179-187.

[7] AOAC - ASSOCIATION OFFICIAL ANALYTICAL CHEMISTRY. Official Methods of Analysis. $16^{\text {th }}$ ed., v. 2, Arlington, VA. USA, 1997.

[8] ARAÚJO, J. M. A. Química de alimentos: teoria e pratica. 2. ed. Viçosa: UFV, 1999. 416 p.:il.

[9] BORGES, P. Do valor alimentar da castanha-do-pará. SAI n. 39. [Rio de janeiro: s.n.], 1967. 38 p.

[10] BRASIL. Resolução $n^{\circ}$ 34/1976. Diário Oficial. Ministério da Saúde, Brasília.

[11] BRASIL. Portaria n 554 de 30 de agosto de 1995. Diário Oficial. Brasília, Secretaria da Agricultura, do Abastecimento e Reforma Agrária.1 Set., Seção 1.

[12] BUllerman, L. B.; HARTMAN, P.; AYRES, J. C. Extraction and analysis of aflatoxins from cured and aged meats. Journal A.O.A.C. v. 52, p. 638-641. 1969.

[13] CÂMARA, G. M. S.;GODOY, O. P.; MARCOS, F. ${ }^{\circ}$, J.; LIMA, U. A Tecnologia da produção. In: CÂMARA, G. M. S.; GODOY, O. P.; MARCOS, F. ${ }^{\circ}$, J.; LIMA, U. A. Mandioca: produção, pré-processamento e transformação agroindustrial.(Série Agroindustrial $n^{\circ} 4$ ). São Paulo: Secretaria da Ind., Com., Ciênc. e Tec., 1982. p. 1-44.

[14] CAMARGO, L. A. A. Estudo químico-bromatológico das castanhas da Bertholletia excelsa, H. B. K., 1968. 43 p. Tese de Doutorado - Faculdade de Farmácia e Odontologia de Araraquara, Universidade Estadual de São Paulo, Araraquara, 1968.

[15] CAMPOS, M. A. P. Fibra: A fração alimentar que desafia os estudiosos. Alim.Nutr., São Paulo, n. 2, p. 5363. 1990.

[16] CASTRO, R. V. de Efeitos quimioterápicos do selênio no câncer da mama. Disponivel em: <http:// www.correionet.com.br/ rvcastro, > Acesso em: 12 ago. 2000.

[17] CAVAlCANTE, P. B. Frutas comestiveis da Amazônia I. Belém, Museu Paraense Emilio Goeldi: ESALQ/ USP. 84 p. 1972.

[18] CAVAlCANTI, M. L. F. Fibras Alimentares. Revista de Nutrição. Campinas, 2 (1): 88-97, jan./jun. 1989.

[19] ChanG, C. C.; GUTEnMANn, W. H.; REID, C. M.; LISK, D. J. Selenium content of Brazil nuts from two geographic locations in Brazil. Chemosphere, v. 30, n. 4, p. 801-802, 1995
[20] ChuZEL, G.; VIlPOUX, O.; CEREDA, M. P. Le Manioc $\mathrm{Au}$ Brésil. Importance sócio-économique et diversité. In: EGBE, T. A.; BRAUMAN, A.; GRIFFON, D.; TRECHE, S. (Eds.). Transformation alimentaire du manioc. Paris: Orstom, 1995. p. $571-579$.

[21] CHUZEL, G.; ZAKHAIA, N.; CEREDA, M. P. Potencialités de nouveaux produits derives du manioc au Brésil. In: EGBE, T. A.; BRAUMAN, A.; GRIFFON, D.; TRECHE, S. (Eds.). Transformation alimentaire du manioc. Paris: Orstom, 1995. p. $63-74$.

[22] COOPERATIVA AGRO-EXTRATIVISTA DE XAPURI-AC. Castanha-do-Brasil (Bertlholletia excelsa, H. B.K.). [Rio Branco: s.n.], 2000.

[23] DIAS, A R. G. Efeito de oxidantes, de ácidos orgânicos e da fração solúvel em água na propriedade de expansão do amido de mandioca fermentado., Campinas. 2002. 149 p. Tese (Doutor em Tecnologia de Alimentos) - Faculdade de Engenharia de Alimentos, Universidade Estadual de Campinas.

[24] FAO - FOOD AND AGRICULTURE ORGANIZATION OF THE UNITED NATION. Amino-acid content of foods and biological data on proteins. Rome, FAO. 1970. p. 62-63.

[25] FAO/WHO/UNU expert consultation. Energy and protein requeriments: $\mathrm{FAO} / \mathrm{WHO}$ nutrition meetings. Geneva: Food and Agriculture Organization/World Health Organization, 1985. Report series 724.

[26] FRANCO, G. Tabela de composição química dos alimentos. São Paulo: Atheneu, 1992. 230p.

[27] GLÓRIA, M. M. e REGitano-D’ARCE, M. A. B. Concentrado e isolado protéico de torta de castanha-doPará: Obtenção e caracterização química e funcional. Ciênc. Tecnol. Aliment., Campinas, v.20, n. 2, p.240245, maio/ago.2000.

[28] HART, F. L.; FISHER, H. J. Modern food analysis. New York, Springer - Verlag, 1971. p. 271-307.

[29] IAL - INSTITUTO ADOLFO LUTZ. Normas analíticas do Instituto Adolfo Lutz. Vol.1. Métodos químicos e físicos para analises de alimentos. 3 ed. São Paulo: USP, 1985.

[30] IMO INDUSTRIES INC. BAIRD ANALYTICAL INSTRUMENTS DIVISION. ICP 2000. Spectrometer user's guide. Bedford, Massachusetts. Dez. 1990.

[31] IP, C.; LISK, D. J. Bioactivity of selenium from brazil nut for cancer prevention and selenoenziyme maintenance. Nutrition and Cancer, v. 21, n. 3, p. 203-12. 1997.

[32] KELY, A. C.; BOOTH, A. N. Aflatoxin effects in livestock. J. Am. Oil Chem. Soc. v. 48, p. 599-604. 1971.

[33] LIMA, U. A. de Industrialização da mandioca. In: CAMARA, G. M. S. Mandioca: produção, pré-processamento e transformação agroindustrial. São Paulo: Secretaria da Ind., Com., Ciênc. e Tec., 1982.

[34] LISK, D. J,; IP, C. Charectization of tissue selenium profiles and anticarcinogenic responses in rats fed natural sources of selenium-rich products. Carcinogenesis. v.14, n. 4, 573-576, 1999.

[35] LOUREIRO, A. A.; SILVA, M. F. Catálogo das madeiras da Amazônia. Belém: SUDAM. v. 1, p. 238-239. 1968.

[36] MARK, S. D.; QIAO, Y. L.; DAWSEY, S. M.; WU, Y.P.;KATKI, H.; GUNTER, E. W.; FRAUMEN, J.F.Jr.; BOLT, W. J.; DONG, Z. W.;TAYLOR, P.R. Prospective study of serum selenium levels and incident esophageal and gastric cancers. J. Nat. Cancer Inst. 2000 nov. 1, 92(21):1753-1763. Disponível em: <www.cirugest.com/ Revisiones/Cir13-07/1307RB01.htm.> El selenio pro- 
tege contra el desarrollo de cáncer de esófago y de estómago. Acesso em: 31.08.2002.

[37] MELO, C. F. M. Castanha-do-pará (Bertholletia excelsa, H. B. K.).In: Conservação dos recursos naturais renováveis. Belém: ADESG, 1977. p. 77-78.

[38] MOURA, E. C. V.; ZUCAS, S. M. Ensaio nutricional da proteína de soja suplementada com farinha de castanha-do-pará. Alimentação, v. 57, p. 6 -17. dez. 1981.

[39] MÜlleR, C. H.; FIGUEIREDO, F. J. C.; KATO, A. K.; CARVALHO, J. E. U. de. A cultura da castanha-doBrasil. Brasília: EMBRAPA. Coleção Plantar, v. 23, 65 p. 1995.

[40] NEVES, C. A. A castanha-do-pará. Rev. de Agricultura. v. 13 , n. 10. p. 1-16. 1938.

[41] OLSON, O. E.; PALMER, I. S.; CARY, E.K.E. Modification of the official fluorimetric method for selenium in plants. J. Assoc. Off. Anal. Chem. v. 58, p. 117-121, 1975.

[42] PARIZEK, J. Dose-response aspects of selenium in nutritional toxicology. In: COMBS, G. F. et al. (Ed.). Selenium in Biology and Medicine. New York: AVI Book, 1987. p. 66-77.

[43] PALMER, I. S.; HERR, A. N. Journal food Scienc. Chicago. Institut of food techonologists. v. 47, p.15951597, 1982.

[44] PROUDLOVE, R. K. Os alimentos em debate: uma visão equilibrada. São Paulo: Varela. 1996. 251p.

[45] PURCHASE, I. F. Aflatoxin residues in feed of animal origin. Ed. Cosmetic. Toxicology, v. 10, p. 531-544, 1972.

[46] RAYMAN, M. P. The Importance of Selenium to Human Health. Reino Unido: The Lancet, p. 233-241, Dec. 2000.

[47] RIBEIRO, M. A. A.; SOLER, R. M.; REGITANO-D'ARCE, M. A. B.; LIMA, V. A. Shelled Brazil nuts canned under different atmospheres. Ciênc. Tecnol. Aliment., Campinas, v. 15, n. 2, p. 105-107, jul,/dez, 1995.

[48] RODRIGUEZ AMAYA, D. B.; VALENTE SOARES, L. M. Survey of aflatoxins, achratoxin A, zearalenone and sterigmatocystin in some Brazilian foods, utilizing a mult-toxin thin layer chromatographic method. J. Assoc. of Anal. Chemistry, v. 72, n.1, p. 22-26, 1989.

[49] SABBATINI, R. M. E. Tudo dá câncer. Disponível em: $<$ http://www.nib.unicamp.br/sabbatin.htm> Acesso em: 25 ago. 2002.

[50] SANTOS, J. B. dos Castanha-do-pará. In: Grande manual globo de agricultura. v. 3. Porto Alegre: Globo, 200p. 1978.

[51] SANTÚRIO, J. M. Disponível em: <http:// www.alimentoseguro.com.br/alimentoseguro.htm / aflatoxina $>$. Acesso em: 25 Ago. 2002.

[52] SOUZA, A. H. Castanha-do-pará: estudo botânico, químico e tecnológico. [Rio de Janeiro: s.n.] SAI n. 23. 63p. 1963.

[53] SOUZA, M. L. Estudos de processos tecnológicos para a obtenção de produtos derivados de castanha-doBrasil (Bertholletia excelsa, H.B.K.). Fortaleza. 1984, 139p. Dissertação (Mestrado em Tecnologia de Alimentos), Universidade Federal do Ceará.

[54] SOUZA, M. L.; HOLANDA, L. F. F. DE; MAIA, G. A.; GASPAR JUNIOR, J. C.; Estudo do processamento e estabilidade de leite de amêndoa da castanha-do-Brasil (Bertholletia excelsa, H.B.K.). Ciência Agronômica. v. 18, n. 1, p. 137-146, Jun, 1987.

[55] SPACKMAN, D. C.;STEIN, W. H.; MOORE, S. Automatic recording apparatus for use the chromatography of aminoacids. Analytical Biochemistry, v. 30, p.11901206, 1958.

[56] SPIES, J. R. Determination of tryptophan in proteins. Analytical Chemistry, v.39, p.1412-1415, 1967.

[57] SRUR, A. U. O.S. Precessamento da castanha-do-Brasil (Bertholletia excelsa, H. B. K.). Campinas. 1976. 59p. Dissertação (Mestrado em Tecnologia de Alimentos) - Faculdade de Engenharia de Alimentos, Universidade Estadual de Campinas.

[58] TATEO, F. Acid composition of the fatty material extracted from seeds of Bertholletia excelsa H.B.K. Ind. Alimentari, v.10, n. 70, p.68-70, 1971.

[59] TEIXEIRA, E. Frutas do Brasil. Rio de Janeiro: MEC/ INL, 1954. 281p.

[60] TROWELL, H. et al. Dietary Fibre, Fibre-Depleted Foods and Disease. London: Academic Press, 1986.

[61] TRUMBO, P.; YATES, A. A.; SCHLICKER, S.; POOS, M. Dietary reference intakes: Vitamin A, vitamin K, Arsenic, Boron, Chromium, copper, iodine, iron, manganese, molybdenum, nickel, silicon, vanadium, and zinc. Journal of the American Dietetic Association, v. 101, n. 3, p. 294-301, march, 2001.

[62] VIEIRA, T. M. F. S.; REGITANO-D“ARCE, M. A. B. Antioxidant concentration effect on stability of Brazil nut (Bertholletia excelsa) crude oil. Archivos Latino Americanos de Nutricion, Guatemala, v. 49, n. 3, p. 271-274, 1999.

[63] WOODROOF, J. G. Tree nuts: production, processesing, products. 2.ed. Westport: AVI Publishing, 1982. $731 \mathrm{p}$.

[64] www.codexalimentarius.net/ccffv10/ffO201s.htm. Circular codex 2001/39-Ffu level of $\mathrm{HCN}$ in cassava. Disponível em < www.codexalimentarius.net $>$. Acesso em 12.08.2002.

[65] SELENIO. Disponível em: <www.oligopharma.com.br/ oligoelementos/selênio/htm. >. Acesso em 07.08.2002.

[66] Oligoelementos. Disponivel em <http:// www.ologofarma.com>. Acesso em 20.10.2002.

[67] SALES MINERALES/SELENIO. Disponivel em: <http:// www.zonadiet.com/salesminerales/selenio $>$. Acesso em 11.09.2002.

\section{6 - AGRADECIMENTOS}

À Fundação de Amparo à Pesquisa do Estado de São Paulo - FAPESP e ao Conselho Nacional de Desenvolvimento Cientifico Tecnológico - CNPq, pela oportunidade, auxílio financeiro e bolsa concedida. 